\title{
AVALIAÇÃO E AUTORREGULAÇÃO DA APRENDIZAGEM
}

Lourdes Maria Bragagnolo Frison

\begin{abstract}
Resumo
Este artigo busca compreender a autorregulação da aprendizagem conceituada como o processo em que os sujeitos estabelecem metas que interagem com suas expectativas e desenvolvem estratégias para alcançá-las, criando condições para que a aprendizagem efetive-se. A avaliação articulada à autorregulação da aprendizagem assume novo significado pelo qual os sujeitos adquirem, por si e com a ajuda do outro, conhecimentos que os permitem rever o caminho percorrido e os possibilitem desenvolver o autoconhecimento e o conhecimento dos que o rodeiam.
\end{abstract}

Palavras-chave: avaliação, autorregulação, aprendizagem.

\section{EVALUATION AND SELF-REGULATION OF THE LEARNING}

\begin{abstract}
This paper aims to understand the self-regulation of the learning process, which is defined as a process where the subjects set targets that are interconnect with their expectations, develop strategies to achieve those targets, so create conditions to reach the effective learning. The evaluation articulated to the learning self-regulation obtains a new meaning where the subjects acquire, on their own and with the aid of the other subject, knowledge that will allow them to review the developed pathway, besides giving them possibilities of developing the self-knowledge and the knowledge of the other human beings that surround them.
\end{abstract}

Keywords: evaluation, self-regulation, learning 


\section{Introdução}

Avaliar é uma necessidade humana. Avalia-se para tomar decisões, para fazer compras, para estabelecer juízos de valor sobre ações, acontecimentos, pessoas ou tarefas. É na escola, porém, que a avaliação assume papel fundamental, pois passa a ser entendida como elemento integrante e regulador da prática educativa, estando intrinsecamente ligada ao percurso dos processos de ensino e de aprendizagem que envolve professores e alunos.

O processo avaliativo depende das opções teóricas, filosóficas e pedagógicas assumidas pelo professor, podendo manifestar-se como um mecanismo de diagnóstico, de acompanhamento do crescimento dos alunos ou ainda como mecanismo de exclusão social. Ao longo da história da educação, a avaliação nem sempre foi encarada da mesma maneira, nem teve uma evolução casual, mas esteve relacionada aos sistemas educativos, à cultura, à evolução da sociedade e ao contexto político-econômico. Por muito tempo acreditou-se que, a partir de testes bem construídos, podia-se medir com exatidão, rigor e isenção as aprendizagens dos estudantes. A complexidade da avaliação foi subestimada, tratada como técnica de medir o conhecimento adquirido, como instrumento de controle e até como forma de opressão do professor. Nessa perspectiva, a avaliação ficou profundamente arraigada ao contexto escolar e ainda hoje tem considerável importância, embora tenha gerado muitas controvérsias e limitações.

Com o surgimento de diferentes concepções de avaliação, começaram a emergir reflexões sobre como avaliar e sua complexidade, abrindo perspectivas para questões relacionadas à prática pedagógica. A avaliação tornou-se um espaço de diálogo, em que a partilha de saberes ou experiências, a clarificação e a negociação dos critérios de avaliação asseguram o rigor e a objetividade do processo avaliativo, contribuindo para uma prática pedagógica mais efetiva. A avaliação constitui-se em uma questão essencialmente pedagógica, que está associada ao desenvolvimento social, profissional e acadêmico das pessoas, sendo também uma questão de desenvolvimento curricular da maior relevância.

Atualmente se começa a falar na função reguladora do processo avaliativo em que os saberes não são os únicos objetivos de avaliação, pois se destaca a relevância de compreender e de apreender conhecimentos para saber aplicálos em situação real.

A avaliação passou a ter uma dimensão qualitativa, exigindo de alunos e professores mudanças tanto no comprometimento pessoal como acadêmico. A 
avaliação pode ser considerada um elemento regulador da prática educativa e da aprendizagem do aluno. O professor, através dela, pode discutir questões que auxiliarão o aluno a autorregular suas aprendizagens. A avaliação apresenta-se, pois, como um processo de desenvolvimento de capacidades que desenvolvam e direcionam estratégias para a consecução de tarefas e a superação dos obstáculos a elas inerentes. A participação autônoma, ativa e planejada do aluno e do professor são componentes indispensáveis. O aluno é percebido como protagonista de sua aprendizagem e o papel do educador, para que o conhecimento avance, é o de intervir e de mediar, considerando as hipóteses já construídas.

\section{Conceituando autorregulação da aprendizagem}

A autorregulação da aprendizagem é definida por teóricos como Veiga Simão (2002, 2004a/b, 2005, 2006); Lopes da Silva (2004a/b), Zimmerman (1989, 1990, 1994, 1998, 2000); Bronson (2000); Zeidner, Boekaerts, \& Pintrich (2000); Rosário (2006), como o processo em que os sujeitos, após estabelecerem metas que interagem com suas expectativas, desenvolvem estratégias para alcançá-las, criando condições para que a aprendizagem se efetive (FRISON, 2006). Para isso, é preciso que a aprendizagem fundamente-se na reflexão consciente sobre a compreensão do significado dos problemas que surgem, decidindo as ações numa espécie de diálogo do sujeito consigo mesmo (VEIGA SIMÃO, 2004a).

Zimmerman (2000) define autorregulação como o reflexo de pensamentos, ações e sentimentos criados pelos próprios sujeitos na interação com o contexto e intencionalmente orientados para a realização dos objetivos, utilizando estratégias cognitivas, metacognitivas, motivacionais e contextuais. $\mathrm{O}$ controle cognitivo é entendido como a capacidade de o indivíduo "deliberadamente controlar e planejar seus próprios processos cognitivos com o fim de alcançar uma determinada meta ou objetivo" (WOLFS, 2000, p.170). A metacognição pode ser entendida como a capacidade de conhecer o próprio pensar e envolve, simultaneamente, a tomada de consciência e o controle da própria cognição. A condição motivacional impulsiona o comportamento na obtenção de metas e planos. O componente contextual, tanto físico quanto social, pode potencializar a aprendizagem.

Segundo Pozo (2002), os aprendizes devem aprender a controlar e regular seus processos cognitivos, assim como formar o hábito de pensar sobre o próprio conhecimento. A aprendizagem autorregulada oferece, portanto, pon- 
tos de referência para desenvolver ações de qualificação que se entrelaçam às experiências vividas, à identidade pessoal e profissional dos sujeitos. Ela é percebida como inseparável do sujeito na relação com sua vida e seu trabalho cotidiano, podendo ser entendida como o "reaprender a aprender" (MORIN, 1990, 1999) ou o "aprender pela autorregulação" (VEIGA SIMÃO, 2004b).

A aprendizagem autorregulada surge numa perspectiva que vai explorar as competências dos alunos e do professor, articuladas ao processo educativo, de modo a tornar a aprendizagem mais efetiva e duradoura. Portanto,

em uma sociedade cada vez mais aberta e complexa, existe uma insistência crescente para que a educação deva estar dirigida para promover aptidões e competências e não só conhecimento fechados ou técnicas programadas (VEIGA SIMÃO, 2004a, p. 45).

A autorregulação é um sistema auto-organizado que dirige e estimula a ação para alcançar uma meta pretendida pelo próprio sujeito ou sugerida/mediada por alguém que tenha participação no processo (educador). Este percurso envolve necessariamente cognições/metacognições, emoções e motivações. Para que a ação seja autorregulada é preciso ter um objetivo a ser atingido, um motivo que provoque a ação, sustentando-a até atingir a meta desejada.

A necessidade de aprender estende-se às atividades sociais, escolares, de trabalho, por isso, afirma-se que jamais houve época em que as pessoas foram instadas a aprender tantos e tão diferentes valores, atividades, competências como atualmente. A sociedade da aprendizagem exige das pessoas contínua dedicação, ritmo acelerado e a preocupação (quase neurótica) de não esquecer o aprendido (POZO, 2002). Esta possibilidade, mais do que um lapso na aprendizagem, pode ser explicada pela dificuldade de entender "como aprender" ou "por que aprender". A aprendizagem formal e informal faz-se ao longo da vida e não somente na escola, pois as cobranças e exigências profissionais são intermináveis. Deve-se, pois, proporcionar aos alunos a possibilidade de desenvolvimento de competências e habilidades que lhes permitam serem capazes de responder às necessidades demandadas pelo contexto escolar e profissional.

Nas pesquisas realizadas nas últimas duas décadas, na área da Psicologia da Educação, os teóricos apresentam vários estudos sobre a autorregulação da aprendizagem, focando o conhecimento, a motivação e a vontade relativos à forma e à maneira de aprender demonstradas pelos sujeitos ao se engajarem em variadas tarefas, em diferentes ambientes de aprendizagem. Eles enfatizam também que, para a ação ser autorregulada, "tem de haver um motivo que a 
incite e a sustente e que prolongue o esforço até atingir a eficácia desejada" (LOPES DA SILVA, 2004a, p. 25).

Face às inquietações decorrentes desta teoria, apresentam-se, neste texto, algumas ponderações sinalizadoras da necessidade de se considerar, na discussão acerca da autorregulação da aprendizagem como campo de saber e de prática educativa, formas metodológicas e organizativas dos processos e dos modos de ação, característicos da construção humana. Ultrapassam-se, pois, as visões que concebem a autorregulação apenas em sua dimensão técnica, metodológica ou como mero campo de aplicação prática de saberes oriundos de diversas área de conhecimento. Através dessa concepção, pretende-se evitar reducionismos e simplificações na construção do conhecimento necessário tanto aos sujeitos em formação quanto aos formadores que atuam na capacitação das pessoas em diferentes espaços educativos.

Ao buscar compreender a autorregulação, é importante analisar os fatores, as fases e os componentes motivacionais, cognitivos, comportamentais, emocionais, sociais implícitos nessa teoria. Os aprendizes, ao autorregularem suas aprendizagens, desenvolvem a autonomia/dependência do educador no contexto escolar ou profissional, causam e geram ordem/desordem em função das aprendizagens e das interferências do meio.

Para Morin (1990), auto-organização significa também autonomia, pois um sistema auto-organizador atua de modo a construir e reconstruir-se de forma autônoma/dependente. Ao construir autonomia, interage com o outro, do meio retira sua autonomia, extrai energia para transformá-la em autorregulação.

Para que ocorra auto-organização é preciso existir dificuldades, perturbações, desafios, problemas e turbulências que estimulem a reação do organismo em relação ao meio. O organismo depende do meio ambiente onde os efeitos e os produtos são necessários para sua própria causa e sua própria produção (FRISON \& SCHWARTZ, 2008, p. 360).

A auto-organização é também recursiva, pois permite um circuito ou um princípio hologramático no qual não existe a causa ou o causador, mas ambos articulam-se recíproca e corresponsavelmente, pois "os produtos e os efeitos são, eles mesmos, produtos e causadores daquilo que os produz" (MORIN, 2000, p. 95).

Para implementar a autorregulação, o professor lança mão de seu conhecimento sobre as pessoas, engloba conhecimentos sobre si, sobre os alunos com os quais trabalha, sobre a instituição/organização à qual pertence e sobre 
o aprender, refletindo como as pessoas aprendem e o que pode ser feito para que elas aprendam mais e melhor.

A tarefa de preparar uma aula ou uma formação pedagógica exige que o professor conheça a natureza da tarefa a que se propõe. Esses profissionais precisam conjugar os conhecimentos referentes ao assunto e a eles incorporar os pré-requisitos que o sujeito apresenta para compreender o assunto abordado, sobre a melhor maneira de poder sistematizar e compreender o que está sendo tratado. Em decorrência dos conhecimentos que o educador tem com referência às pessoas e às tarefas, ele pode propor atividades e preparar estratégias pertinentes ao seu desenvolvimento. O sujeito aprendiz precisa, da mesma forma que o educador, internalizar informações sobre o assunto para saber lidar com situações que requerem a articulação de uma estratégia de solução. Desse modo, o conhecimento do educador pode ser pensado juntamente com o do aprendiz, constituindo um sistema integrado de informações internalizadas, relacionadas ao assunto a ser tratado, ao sujeito da aprendizagem e à estratégia pedagógica a ser trabalhada.

\section{Regulação e autorregulação: estratégias para a aprendizagem}

Regulação é o termo utilizado em referência aos processos específicos que visam criar, implementar e ajustar estratégias de ensino às aprendizagens dos sujeitos. A regulação tem como objetivo contribuir diretamente para a progressão das aprendizagens, o que significa acompanhar o aprendiz em seu desenvolvimento. A aprendizagem é destaque em todas as ações humanas, não só pelas condições cognitivas que o sujeito apresenta, mas também pelos fatores motivacionais que o envolvem. Estes fatores motivacionais levam o indivíduo a dirigir seu próprio comportamento em função de metas e aspirações pessoais ou profissionais e a exercer algum tipo de controle sobre seus sentimentos, pensamentos, comportamentos, de modo a realizar a tarefa desejada.

Essa mudança de concepção provocou alterações no conceito de aprendizagem. Ela deixa de ser pensada apenas como recepção e acumulação de conhecimentos recebidos e passa a ser algo que transforma aquele que aprendeu para poder aplicar o conhecimento em situações de vida pessoal ou profissional. Cabe ao professor proporcionar situações de questionamentos e desafios para que os alunos possam regular estratégias de ação, a fim de atingirem as metas planejadas e pretendidas. O sujeito torna-se, portanto, um interventor ativo em seu processo de aprendizagem (LOPES DA SILVA, 2004b).

A regulação, ao ser provocada e estimulada pelo professor, reveste-se 
de ações que organizam/reorganizam propostas de trabalho, de planejamento, adequando-as às necessidades dos aprendizes. Ela mobiliza diferentes estratégias que estimulam o desenvolvimento dos processos de aprendizagem, não para o desenvolvimento do conteúdo, mas para a organização de pautas e de ações facilitadoras que permitam desenvolver a capacidade de administrar projetos para a construção das aprendizagens (FRISON, 2006).

Nessa afirmação está implícita a intervenção do professor, em situação de aprendizagem, orientando/reorientando a diversificação dos processos educativos dos aprendizes. Utilizar recursos e definir ações, no sentido de possibilitar aproximações do sujeito com o conhecimento, estimula a autorregulação. Nessa perspectiva, podem-se adotar estratégias de ensino para discutir e analisar diferentes questões, oportunizando que cada aluno expresse suas ideias e exponha suas reflexões. É possível, além disso, propor desafios, atividades de estudo e de pesquisa, sugerir leituras e levar o aprendiz a interagir, através de debates e reflexões, com colegas que dominam determinado tema.

Zabala (1998) salienta que a aprendizagem reguladora depende de como o sujeito, ao se confrontar com a necessidade de construir novos conhecimentos, aprende a lidar com os processos de ensino e de aprendizagem. $\mathrm{O}$ aluno, ao ser provocado a investigar, a pesquisar e a elaborar suas próprias produções (suas metas), reveste-se de uma energia que o impulsiona a fazer o melhor e a atingir patamares de aprendizagem desconhecidos por ele e pelo educador.

Perrenoud (1999) utiliza a expressão "regulação dos processos de aprendizagem" para designar o conjunto das operações metacognitivas e da interação realizada pelo sujeito com o meio, constantemente modificadas pelas conquistas em seu processo de aprendizagem. Define metacognição como o conhecimento que alguém tem de sua própria cognição, da capacidade que tem de se conhecer e de refletir sobre si próprio, passando pela capacidade cognitiva, por competências e emoções. Esse processo pode ser controlado e desenvolvido pelo sujeito através de suas conviç̧ões, do conhecimento que tem de si e dos outros. A avaliação requer sentido pedagógico, porém só o tem a partir da metacognição, quando o aluno passa a refletir sobre si e sobre o que sabe, pois assim ele também desenvolve a capacidade de controlar e desenvolver seus conhecimentos.

A autorregulação sugere promover algo diferente, provocando novos contextos e novas situações de aprendizagem, atividades diversas, variadas abordagens e pluralidade de configurações do grupo de alunos. Até mesmo na maneira de organizar um grupo ou implementar uma tarefa está implícita a regulação proposta pelo educador. A regulação das aprendizagens parte de uma 
ação intencional, que interfere no processo educativo, mantendo ou reorganizando a trajetória planejada, com vistas ao alcance da aprendizagem desejada.

Trata-se, portanto, de um processo dinâmico, contínuo e que supõe considerar, de modo especial, alguns aspectos da ação pedagógica: as intenções, os objetivos educativos estabelecidos. Deve-se considerar também os meios utilizados durante o processo para alcançar essas intenções ou objetivos e a forma de avaliar sua efetividade, tendo em vista a programação das aprendizagens e as estratégias utilizadas para ajustar o ensino às necessidades de aprendizagem.

Perrenoud (1999) distingue regulação direta e regulação indireta. A primeira, centrada na atividade do sujeito, caracteriza-se como uma intervenção em seu funcionamento intelectual. A segunda é uma ação sobre as condições de aprendizagem, motivação, participação, ambiente, envolvimento com o trabalho, organização da atividade e da situação didática. Perrenoud (1999), no entanto, aponta alguns obstáculos à regulação eficaz das aprendizagens: a ênfase que a maioria dos sistemas educativos reserva à lógica pura e simples do repasse de informações em detrimento da lógica da aprendizagem; a dificuldade para compreender como se processam as aprendizagens dos sujeitos, os mecanismos de elaboração do raciocínio, da compreensão e da memorização; as rupturas ou descontinuidades nos processos de regulações que, embora bem iniciadas, ficam inacabadas; a tendência a dar prioridade à regulação da tarefa, em vez de regular a aprendizagem como processo.

O que ameaça a ideia de regulação das aprendizagens é a confusão existente entre aprendizagem e atividade de trabalho, pois, se o sujeito está engajado na atividade proposta, entende-se que ela contribui para consolidar sua aprendizagem. Nem sempre as intervenções propostas pelo professor são, no entanto, reguladoras, visto que muitas vezes representam apenas a cobrança da atividade que se configura como tarefas a serem realizadas pelo grupo todo, sem atender as necessidades específicas. O educador, normalmente, atém-se primeiro às atividades e à progressão das tarefas e não à progressão das aprendizagens subjacentes. Isso explica por que aprendizagem e atividade de trabalho não são a mesma coisa, pois a realização de uma tarefa certamente não significa dizer que o sujeito aprendeu ou não aprendeu, já que isso depende de seu envolvimento na realização e da natureza do auxílio prestado pelo profissional da educação.

Regular a atividade equivale a manter o clima de trabalho, a coesão do grupo e a continuidade da ação, no sentido de desenvolvê-la. Regular as aprendizagens também significa contribuir com o desafio cognitivo e com todos os 
processos suscetíveis, fortalecendo esquemas ou saberes (PERRENOUD, 1999). Nem toda atividade gera automaticamente aprendizagem, pois não se trata de multiplicar atividades externas, mas de estimular o aprendiz para a regulação de seus processos de pensamento e sua aprendizagem, uma vez que, desde seu nascimento o ser humano é capaz de representar, mesmo que parcialmente, seus mecanismos mentais. Para Perrenoud (1999), essa definição tem sentido amplo, de modo a englobar a regulação e a autorregulação que remetem à ideia de metacognição. Segundo ele, toda regulação é, em última instância, autorregulação, já que intervenções externas agem no sujeito se forem por ele percebidas, interpretadas e assimiladas.

$\mathrm{Na}$ mente humana, a regulação só pode ser autorregulação se houver adesão à tese de que nenhuma intervenção externa age se não for percebida, interpretada e assimilada pelo sujeito. Nessa perspectiva, toda a ação educativa pode estimular o autodesenvolvimento, a autorregulação e a autoaprendizagem. Para que isso ocorra, é necessário que o professor e o aluno tracem caminhos que demonstrem que eles sabem aonde querem chegar. Pode-se fazer uma correlação com a história de Alice (Alice no País das Maravilhas, de Lewis Carrol), quando ela perguntou ao gato de Cheshire qual o caminho que deveria seguir para sair daquele lugar. Ele respondeu: "isso depende muito de para onde você quer ir". Ela disse: "não importa para onde eu vá, desde que eu chegue a algum lugar". "Isso acontecerá de qualquer maneira”, respondeu o gato, "desde que você ande durante algum tempo".

Na proposta de autorregulação da aprendizagem, contrariamente a Alice, deve-se planejar o caminho a ser seguido, deve-se traçar metas para chegar ao lugar previamente planejado, mesmo que, ao percorrê-lo, modifiquem-se os planos, pois, frente à multiplicidade de possibilidades, pode se pensar em outras estratégias. Isso significa que, para regular a aprendizagem é necessário fazer escolhas as quais estão atreladas ao investimento pessoal. A ação desencadeada pelo professor serve para que o sujeito/aluno sinta-se estimulado a autorregular sua aprendizagem (FRISON, 2006).

Autorregulação supõe a capacidade de o sujeito refletir sobre o processo percorrido, desenvolvendo assim a capacidade de autoavaliar-se com o objetivo de realizar correções ou ajustar metas e estratégias necessárias ao processo da aprendizagem. Ele não deve ter medo do erro, pois, neste caso, o erro passa a ser parte do processo e não resultado de sua ação. O erro reflete uma hipótese de conhecimento e surge justamente pela imersão no conhecimento em questão. Ele nasce da dúvida. Punir o erro seria o mesmo que punir a dúvida (CUNHA, 2007). 


\section{Significado da avaliação no contexto da autorregulação}

A avaliação assume, a partir da prática pedagógica utilizada, novo significado. Pela dimensão da autorregulação os sujeitos adquirem, por si e com a ajuda do outro, conhecimentos que lhes permitem rever o caminho percorrido, além de possibilitar-lhes desenvolver o autoconhecimento e o conhecimento dos que o rodeiam. Permite também que construam, simultaneamente, representações mentais internas de si e dos outros. Para auxiliar o aluno a progredir e refletir sobre determinadas questões, mesmo sobre assuntos por ele desconhecidos, o professor precisa provocar inquietações que podem ser usadas para organizar a progressão/regulação da aprendizagem. Neste sentido, é eficaz criar estratégias para que todos possam dominar a tarefa de modo a aprenderem significativamente.

O professor, ao avaliar o desempenho do aluno, analisa com ele os avanços conquistados, as aprendizagens construídas ou emergidas a partir de diferentes metodologias desenvolvidas, relacionadas à vida real. Ao investigar a realidade contextual, o aluno envolve-se, aprende, constrói e reconstrói conhecimentos. Neste sentido, a prática de avaliação tradicional, baseada somente em testes, seria insuficiente e até totalmente desajustada, pois tenderia a ignorar as competências que vão para além da aquisição do conhecimento. Destaca-se a necessidade de coerência entre avaliação, metodologia e estratégias utilizadas, fazendo coincidir as atividades de aprendizagem com as propostas avaliativas. A avaliação, desta forma, passará a ser parte integrante dos processos de ensino e da aprendizagem e assumirá seu papel regulador.

A regulação dos processos de aprendizagem pode surgir da interação entre os sujeitos e os diferentes ambientes educativos (dimensão contextual), ou da atividade metacognitiva do próprio indivíduo (dimensão cognitiva), ou quando este toma consciência de seus erros e acertos, ou de sua maneira de confrontar-se com os obstáculos (dimensão motivacional). Para aprender, o sujeito não deixa de operar regulações intelectuais. Perrenoud (1999) salienta que a regulação faz parte de uma "causalidade teleonômica" com anéis que modificam o presente em função de uma referência ao futuro desejado.

A autorregulação prevê que o sujeito tenha intencionalidade, que trace caminhos e os percorra rumo à aprendizagem. Mesmo assim, nem sempre é possível identificar as interações favoráveis e necessárias e compreender exatamente por que e como otimizá-las. A fim de trabalhar objetivando a aprendizagem autorregulada, é preciso estar atento de modo a poder intervir no curso da atividade, de forma a provocar seu desenvolvimento. Para garantir a 
regulação, o professor precisa dispor de informações pertinentes, confiáveis, estimulando e criando intervenções apropriadas para que os alunos e o grupo possam interpretá-las corretamente, em tempo hábil para efetivação da aprendizagem.

O conceito de autorregulação da aprendizagem surge, pois, articulado ao processo educativo, em uma perspectiva que vai explorar as competências das pessoas, neste caso dos alunos e dos professores, de modo a tornar a aprendizagem mais eficaz, efetiva e fundamentalmente mais duradoura. Pela autorregulação, o professor considera o aluno/aprendiz alguém capaz de criar as próprias condições, de atribuir valor que prolongue a aprendizagem, tornado-a mais relevante e útil. A autorregulação tem por objetivo, além da obtenção de conhecimentos, o processo de saber fazer, envolvendo o desenvolvimento de competências que oportunizam a construção de soluções para as várias emergências decorrentes dos diferentes contextos.

Saber (construir conhecimentos específicos, com ou sem ajuda do educador) e saber fazer (aplicar os conhecimentos construídos) fazem parte do conjunto de ações que torna o sujeito um SER autorregulado. Nestes três pontos - saber, fazer e ser - estão subjacentes os pilares da educação do futuro (DELORS; 1999), que visam tornar o aprendiz um sujeito cognoscente, capaz de construir conhecimento. Essa aprendizagem, segundo Vygostky (1994), acontece mediada pelo conhecimento do outro, na relação com o outro.

A regulação da aprendizagem pode ser feita por meio de pequenas orientações, questionamentos, provocações ou estímulos no momento em que o aprendiz está envolvido com uma dificuldade concreta. Inúmeras intervenções reguladoras não têm tido efeito, porque permanecem inacabadas ou muito isoladas, ou seja, o professor inicia o processo de auxiliar o sujeito a aprender, fazendo articulações e estabelecendo relações entre os saberes, porém, no momento de aprofundar, refletir e construir novos saberes ou de voltar atrás e procurar outros caminhos, o educador não o faz, muitas vezes provocado por outras urgências. Rompe-se, desta forma, a construção da aprendizagem do aluno (PERRENOUD, 1999).

\section{Considerações finais}

Na concepção da aprendizagem autorregulada, consideram-se as ações, os comportamentos, as significações, as experiências, os valores, inclusive as emoções e os sentimentos do sujeito aprendente. O sujeito não pode ser avaliado apenas pelas mensurações quantitativas, mas também deve sê-lo pela ca- 
pacidade de utilizar seus conhecimentos no dia a dia e de resolver problemas. A avaliação compreende, portanto, todas as experiências, competências, conhecimentos anteriores, sentimentos, valores e modo de se organizar que possam estar envolvidos no processo de aprender. A sociedade atual apresenta crescente insistência para que a educação se volte à promoção de aptidões e competências e não só à aquisição de enorme quantidade de conhecimentos programados (VEIGA SIMÃO, 2004a). O construto da teoria da aprendizagem autorregulada contribui para que o sujeito seja mais participativo, ativo e dinâmico em seu processo de aprendizagem.

Não é suficiente propor projetos inovadores ou apelar para a criatividade dos alunos para que eles se mobilizem e assumam a própria aprendizagem. Os saberes não se encontram apenas no plano didático, eles também se encontram no plano subjetivo cognitivo/metacognitivo expresso pelo desejo de aprender. A informática e os recursos audiovisuais podem servir como intervenção intermediária para confrontar o aprendiz com situações que o permitam ver diferentes estratégias, a fim de escolher a alternativa mais adequada ao estudo a que se propõe. A ação é fator de regulação do desenvolvimento e das aprendizagens, porque estimula o aprendiz a acomodar, diferenciar, (re)organizar seus esquemas de representação, de percepção e de ação propriamente dita.

É preciso organizar estruturas de ação menos dependentes do educador e mais centradas no aluno. Sua ação deve ser autônoma, mas também articulada com a do professor, para que trabalhem em sintonia, interconectados na busca da aprendizagem pretendida. Não se trata, portanto, de formar e multiplicar ações externas para envolver os sujeitos, mas de estimular que o sujeito autorregule seus processos de pensamento e de aprendizagem. A autorregulação passa a ser o motor principal do progresso na aprendizagem, pois coloca os sujeitos aprendizes, quer alunos, quer trabalhadores, tão frequentemente quanto possível, em situações de confronto, de troca, de interação e de tomada de decisão, que os forçam a se projetarem; a exporem explicações, justificativas, argumentações; a defenderem suas ideias.

A participação ativa e planejada dos sujeitos nos processos de ensino e de aprendizagem torna-se, pois, componente indispensável. Se o professor deseja trabalhar com a perspectiva de autorregulação da aprendizagem precisa perceber a coerência e a necessidade do estabelecimento de dispositivos didáticos nas propostas a serem trabalhadas, percebendo a necessidade de oportunizar e estimular permanentemente a reflexão sobre o porquê e sobre a forma de fazer determinado trabalho. Nessa reflexão, está posta a oportunidade de iniciar a construção da regulação da aprendizagem, porque, no decurso 
das ações, o sujeito não deixa de operar regulações intelectuais. Na mente humana, toda regulação, em última instância, só pode ser autorregulação se for percebida, interpretada e assimilada pelo sujeito.

Para Lopes da Silva (2004b), o construto da autorregulação implica o desenvolvimento de competências que permitem ao sujeito diagnosticar de modo realista o que sabe e o que necessita aprender; organizar, planejar e desenvolver planos de aprendizagem; determinar objetivos e selecionar estratégias para fazer a atividade ou o trabalho proposto. Implica também saber monitorar os procedimentos utilizados, autotestar suas possibilidades, autoavaliar e autocorrigir-se. Essas competências cognitivas emergem da capacidade do sujeito e estão aliadas a seus atributos, à sua força de vontade, à sua aprendizagem e também aos estímulos manifestos no local de trabalho. A ação educativa/pedagógica estimula o autodesenvolvimento, a autoaprendizagem, a autorregulação da aprendizagem do sujeito e, com sua ação, modifica o meio, ao entrar em interação com ele (PERRENOUD, 1999).

Como o sujeito dirige sua ação tem a ver com suas características pessoais, suas emoções, motivações e cognições. O aluno/aprendiz pode atribuir à meta a ser atingida ou perseguida alta, moderada ou pouca importância. A autorregulação é esse sistema organizado que permite à pessoa gerir os próprios recursos, de modo a atingir os objetivos a que se propõe.

\section{Referências}

BRONSON, M. B. Self-regulation in early childhood: nature and nurture. New York: The Guilford Press, 2000.

CUNHA, M. I. Possibilidades e desafios do processo avaliativo. Anotações da palestra proferida por ocasião do VI Seminário de Formação Docente, Porto Alegre: FAPA, 2007.

DELORS, J. Um tesouro a descobrir. São Paulo: Cortez, 1999.

FRISON, L. M. B. Auto-regulação da aprendizagem: atuação do pedagogo em espaços não-escolares. Tese (Doutorado em Educação) Pontifícia Universidade Católica do Rio Grande do Sul. Porto Alegre: PUCRS, 2006.

\& SCHWARTZ, S. Aprendizagem auto-regulada e autonomia: articulações com o conceito de erro construtivo. IN.: ABRAHÃO, M. H. (Org). Professores e alunos: aprendizagens significativas e comunidades de práticas educativas. EDIPUCRS, 2008. 
LOPES DA SILVA, A. A auto-regulação na aprendizagem: a demarcação de um campo de estudos e de intervenção. In: LOPES DA SILVA, A.; DUARTE, A. M.; SÁ, I.; VEIGA SIMÃO, A. M.. Aprendizagem auto-regulada pelo estudante: perspectivas psicológicas e educacionais. Porto: Porto Ed., 2004a, p. 17-39.

. Questões e problemas: suscitar a reflexão e a investigação. In:

; Aprendizagem auto-regulada pelo estudante: perspectivas psicológicas e Educacionais. Porto: Porto Ed. 2004b. p. 107-117.

MORIN, E. Introdução ao pensamento complexo. 2. ed. Lisboa: Inst. Piaget, 1990.

Alegre: Sulina, 1999.

. O Método III: o conhecimento do conhecimento. 2. ed., Porto

A cabeça bem feita: repensar a reforma reformar o pensamento.

Rio de Janeiro: Bertrand Brasil, 2000.

PERRENOUD, P. Avaliação: da excelência à regulação das aprendizagens: entre duas lógicas. Porto Alegre: Artmed, 1999

POZO, J. I. Aprendizes e mestres: a nova cultura da aprendizagem. Porto Alegre: Artes Médicas, 2002. 296p.

ROSÁRIO, P. Visão das teorias sobre a auto-regulação da aprendizagem. Palestra proferida por ocasião do Seminário: auto-regulação da aprendizagem, na Faculdade de Psicologia e Ciências da Educação na Universidade de Lisboa. Lisboa. Anotações pessoais, 07 de março de 2006.

VEIGA SIMÃO, A. M. A aprendizagem estratégica: uma aposta na autoregulação, Lisboa: Desenvolvimento Curricular, Ministério da Educação, 2002.

. O conhecimento estratégico e a auto-regulação da aprendizagem. Implicações em contexto escolar. In: LOPES DA SILVA, A.; DUARTE, M.; SÁ, I.; VEIGA SIMÃO, A. M. Aprendizagem auto-regulada pelo estudante: perspectivas psicológicas e educacionais. Porto Editora: Porto, 2004a. p. $77-87$.

. Integrar os princípios da aprendizagem estratégica no processo formativo dos professores. In: Aprendizagem auto-regulada pelo estudante: perspectivas psicológicas e educacionais. Porto: Porto Editora, 2004b. p. 95-104. 


\section{Programa de Estudos da Aprendizagem Auto-regulada}

(PEAAR). Lisboa: Faculdade de Psicologia e de Ciências da Educação. Universidade de Lisboa. Disponível em: <http://www.fpce.ul.pt/ investigacao/centros/autoregulacao/>. Acesso em: 10 de maio de 2005.

Auto-regulação da aprendizagem: um desafio para a formação de professores. In: BIZARRO, R.; BRAGA, F. (Org.). Formação de professores de línguas estrangeiras: reflexões, estudos e experiências. Porto: Porto Ed., 2006. p. 192-206.

VYGOTSKY, L. S. A formação social da mente. São Paulo: Martins Fontes, 1994 .

ZABALA. M. A Prática Educativa: como ensinar. Porto Alegre: Artmed, 1998.

ZEIDNER, M.; BOEKAERTS, P.; PINTRICH, P. Handbook of self-

Regulation. New York: Academic Press, 2000. p. 13-39.

ZIMMERMAN, B. J. A social cognitive view of self-regulated learning. J. Educ. Psychol. n. 81, 1989. p. 329-339.

. Attaining self-regulation: a social-cognitive perspective. In: BOEKAERTS, M.; PINTRICH, P.; ZEIDNER, M. (Org.). Handbook of selfregulation. New York: Academic Press, 2000, p. 13-39.

Developing self-fulfilling cycles of academic regulation: an analysis of exemplary instructional models, In:. SKUNK, D.; ZIMMERMAN, B. J. (Org.). Self-regulated learning: from teaching to self-reflective practice. New York: The Guilford Press, 1998. p. 1-19.

Dimensions of academic self-regulation: a conceptual framework for education. In: ZIMMERMAN, B. J.; SCHUNK, D. H. (Org.). Selfregulation of learning and performance: issues and educational applications. New Jersey, Lawrence Erlbaum, 1994. p. 3-24.

; MARTINEZ PONZ, M. Student differences in self-regulated

learning: relating grade, sex and giftedness to self-efficacy and strategy use. Journal of Educational Psychology. v. 82, n. 1, 1990, p. 51-59.

WOLFS, J. L. Análise das práticas educativas que visam à participação do aluno na avaliação diagnóstica, na condução e na regulação de suas aprendizagens. In: J. GRÉGOIRE et al. (org.). Avaliando as aprendizagens: os aportes da psicologia cognitiva. Porto Alegre: Artmed, 2000, p. 169-179. 
Lourdes Maria Bragagnolo Frison

Doutora em Educação pela PUCRS. Professora da UFPel/RS.

E-mail para correspondência:

lfrison@terra.com.br 